\title{
Fake images of the SARS-CoV-2 coronavirus in the communication of information at the beginning of the first Covid-19 pandemic
}

\author{
Celia Andreu-Sánchez; Miguel-Ángel Martín-Pascual
}

Nota: Este artículo se puede leer en español en:

http://www.elprofesionaldelainformacion.com/contenidos/2020/may/andreu-martin_es.pdf

How to cite this article:

Andreu-Sánchez, Celia; Martín-Pascual, Miguel-Ángel (2020). "Fake images of the SARS-CoV-2 coronavirus in the communication of information at the beginning of the first Covid-19 pandemic". El profesional de la información, v. 29, n. 3, e290309.

https://doi.org/10.3145/epi.2020.may.09

Manuscript received on April 20 2019 Accepted on May $5^{\text {th }} 2020$

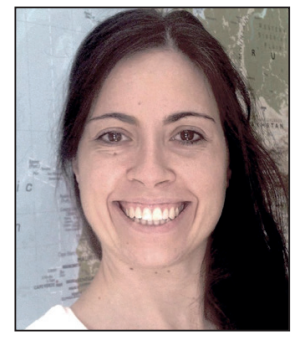

Celia Andreu-Sánchez $\bowtie$ https://orcid.org/0000-0001-9845-8957

Universitat Autònoma de Barcelona Departament de Comunicació Audiovisual i Publicitat, Neuro-Com Research Group Serra Húnter Fellow

Edifici I. Campus Bellaterra.

08193 Cerdanyola del Vallès (Barcelona), Spain.

celia.andreu@uab.cat

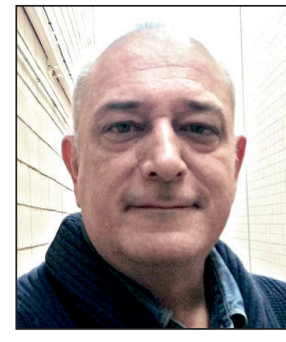

Miguel-Ángel Martín-Pascual https://orcid.org/0000-0002-5610-5691

Universitat Autònoma de Barcelona Departament de Comunicació Audiovisual i Publicitat, Neuro-Com Research Group. Instituto de Radiotelevisión Española Corporación RTVE

Mercè Vilaret, 1. 08174 Sant Cugat del Vallès (Barcelona), Spain. miguelangel.martin@rtve.es

\begin{abstract}
The first real images of SARS-CoV-2, the coronavirus that causes Covid-19, were obtained between January 24 and March 5, 2020 using various electron microscopy techniques. However, since March 2020, it has been most common to see drawn, designed, or interpreted images in three dimensions, sometimes even representing different or directly invented viruses. This analysis studies a sample of images supposedly of SARS-CoV-2 that appeared at the beginning of this pandemic on the internet. Fake images or imaginary illustrations of the Covid-19 coronavirus predominate in all sources of information examined, except for those documented in encyclopedias or scientific articles. Rather than real images, the media have used more fake images of the coronavirus, often from repositories or paid stocks, usually freely available. When presenting SARS-CoV-2 coronavirus content, the use of fake, unrealistic, esthetically retouched illustrations is more common than actual or scientific photographs of the virus. The reference image used in the media and other information sources of the coronavirus that causes Covid-19 is a retouched three-dimensional, color design image for illustration rather than an actual image. The original, real images of the coronavirus did not have the expected informative presence in an emergency situation. The use of unrealistic images of the SARS-CoV-2 coronavirus seems to be a manifestation of a low-intensity infodemic. However, information professionals must use rigorous images to support their information, also in the case of the Covid-19.
\end{abstract}

\section{Keywords}

Covid-19; SARS-CoV-2; Coronavirus; Disinformation; Infodemic; Pandemics; Fake images; Scientific information; Scientific documentation; Information sources; Databases; Repositories; Scientific photography. 


\section{Introduction}

The Covid-19 pandemic has caused a great increase in scientific information as well as unscientific and pseudoscientific information, uniting viral disease with viral information (Depoux et al., 2020; Garrett, 2020; Li et al., 2020). This has resulted in pressure on health systems (Legido-Quigley, 2020) as well as the media and its consumers, who today are transformed into prosumers (Toffler, 1980), i.e., producers of the same information they consume, creating waves of digital disinformation, discrediting, and at times even racism (Shimizu, 2020). The term "infodemic" became popular (Hua; Shaw, 2020; The lancet, 2020) when, on February 15, 2020, the director of the World Health Organization (WHO) said:

"We're not just fighting an epidemic; we're fighting an infodemic" (Adhanom-Ghebreyesus, 2020).

This new term had not been used in the social sciences until 2020 (Nielsen et al., 2020). On April 19, 2020, Google Scholar returned 192 articles with the word "infodemic" in the title.

Nor should we forget the surprising number of scientific articles that have led to this information pandemic (Torres-Salinas, 2020), including medical publications, comments, reviews, and the recent ubiquitous fad towards preprints without peer review. In the first 10 weeks of 2020, over 1000 indexed articles on Covid-19 were published by the scientific community (data from the Web of Science database); for example, the Covid-19 Open Research Dataset (Cord-19), a database of nearly 44,000 articles, includes free full access to 29,000 articles about Covid-19 and similar coronaviruses. In the media, the demand for high-quality information also increased in public media services. According to the European Broadcasting Union ( $E B U)$, the world's largest public media alliance, the audience for nightly news broadcasts on television increased by $20 \%$ among youth and the audience for online news increased by 2.7 -fold in the first two weeks of March 2020 (European Broadcasting Union, 2020a). The British government's Office of Communications (Ofcom) noted that in the first week of confinement, $99 \%$ of the online population went online looking for information and $24 \%$ of those did so more than 20 times. As the $E B U$ broadcaster's audience rose, the $B B C$ was consulted by four out of five people who connected (Ofcom, 2020). In times of emergency, such as the Covid-19 crisis, this increase in audiences has a direct connection with the recovery of the credibility of traditional media such as television, which acquire a special preponderance and prominence (Casero-Ripollés, 2020). Further longitudinal studies that compare media consumption habits before, during, and after the 2020 Covid-19 pandemic will be required. The EBU's Media Intelligence Service believes that media consumption habits will return to normal after the crisis (European Broadcasting Union, 2020b).

More or less detailed illustrations of the coronavirus causing the pandemic soon appeared on television, in popular science articles, on blogs, on social media, and in the online and print press. There is great disparity in the characterizations of the SARS-CoV-2 coronavirus in the media, following the rapid recognition of its nature and structure as responsible for the Covid-19 disease. The outbreak of the disease was reported on December 31, 2019 in China, and the WHO decreed a state of emergency on January 30, 2020 and declared a pandemic on March 11, 2020. Biomedical research, despite the scant initial information, advanced at surprising speed. The genetic characterization and sequencing of the new virus, then still called Wuhan-Hu-1 or 2019-nCoV, was achieved during the month of January 2020 (Wu et al., 2020 ; Wu et al., 2020b). On February 11, the term "severe acute respiratory syndrome coronavirus 2" (SARS-CoV-2) was proposed (Gorbalenya, 2020).

A little earlier, on January 24, the Chinese Center for Disease Control and Prevention (CCDC) shared the first image of the coronavirus, still without its final name, obtained by electron microscopy (National Microbiology Data Center, 2020) (see Figure 1a). It was not of high quality, but the genetic sequence of the virus had been obtained. Therefore, on February 13 , the Rocky Mountain Laboratories (RML), belonging to the National Institute of Allergy and Infectious Diseases (NIAID) in the USA, revealed new high-resolution images, captured a few days earlier from a US patient infected with Covid-19 (De-Wit; Fisher, 2020). They used two techniques in different scanning and transmission electron microscopes. Electron microscopes use electrons instead of visible light and can magnify an image up to a million times (Egerton, 2016).

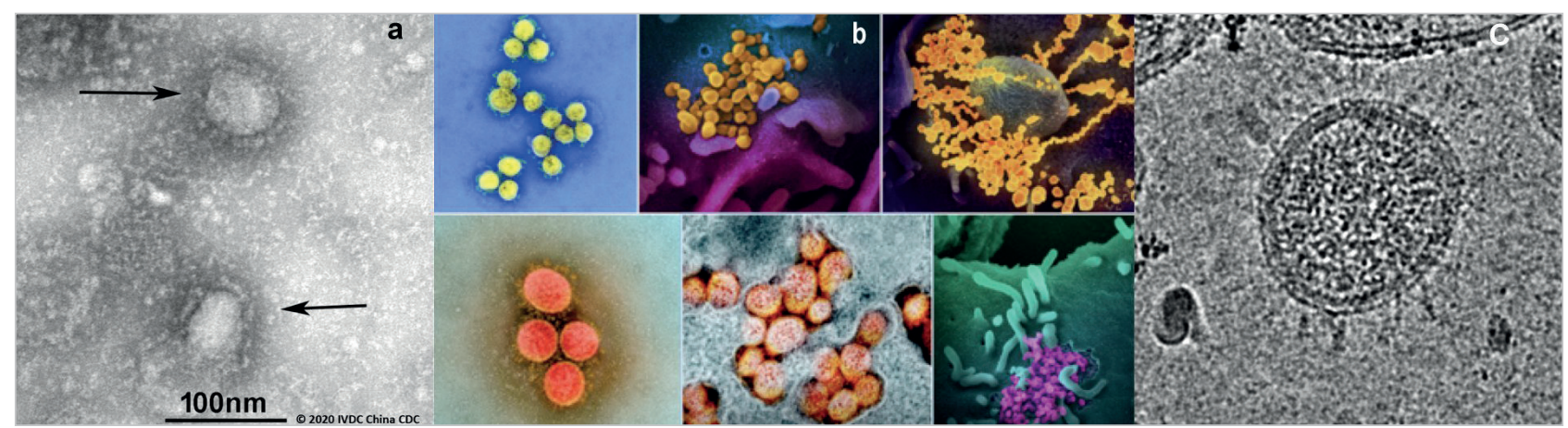

Figure 1. First real images of SARS-CoV-2. CCDC (a); NIAID (b) and Cryo-EM Centre, Shenzhen, China (c).

a. $h$ ttp://nmdc.cn/nCov/en

b. https://www.flickr.com/photos/niaid/albums/72157712914621487

c. https://www.biorxiv.org/content/10.1101/2020.03.02.972927v1.abstract 
The images were published in an open-access Flickr catalog, retouched in false color to enable easy recognition of the presence of SARS-CoV-2 (see Figure 1b). Structural and morphological presentations of the coronavirus, including the first images produced by cryogenic electron microscopy (cryoEM) at higher resolution, were also obtained very quickly and published on March 5, 2020 (Liu et al., 2020) (Figure 1c).

Beyond the actual images, the first public-domain model of the SARS-CoV-2, designed in 3D, emerged on January 30, 2020 from the Center for Disease Control and Prevention $(C D C)$ (Figure 2). This reasonably scientific reconstruction reveals the morphology of the SARS-CoV-2 coronavirus (Eckert; Higgins, 2020), including the striking protein spikes that adorn its surface, looking like a surrounding corona and leading to the name coronavirus. These protein spikes are what allow the virus to enter human cells.

Many variations of this image have emerged. It even appears, with minor changes, in many paid photo repositories; for example, it is available on Getty Images with slight modifications for 475 euros for professional use.

When reporting on the pandemic, the media have shown many similar images. Although coronaviruses have a similar structure, many sources of information and designers have transformed the protein spikes into long tentacles, either by adapting old repository images or by using images from other previous viruses that do not correspond to the cause of Covid-19 (Figure 3).
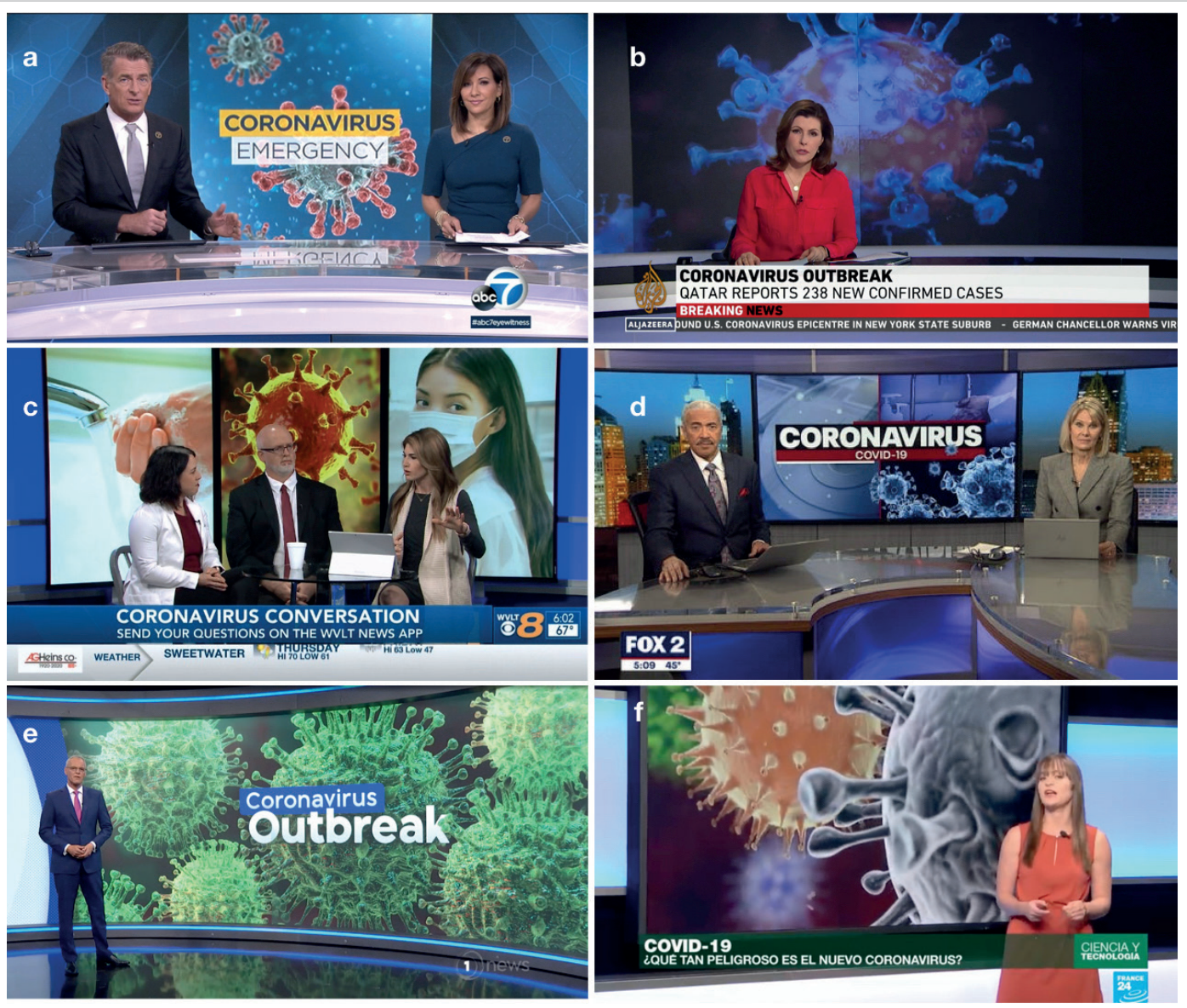

Figure 3. Some examples of the use of nonreal images of the coronavirus and other viruses from image repositories, in the TV news. a. Local news in $A B C$, USA.

b. News in Al Jazeera, Qatar.

c. News in Channel 8 in CBS/MyNetwork TV, USA.

d. Breaking news, Fox2, USA.

e. News in Nzdt, New Zealand.

f. News in Spanish, France24, France. 
Many images are retouched by media design services to adapt the color and other attributes of the coronavirus to their brand image (Figure 4). Most of them do not correspond to the appearance of SARS-CoV-2 either, but rather other, influenza viruses, feline viruses, models touched up according to scientific criteria, or they are just imaginary (Figures 3, 4, 5a, 5b). In the period between March 10 and April 17, 2020, it was unusual to use actual images of the coronavirus in the daily news (Figures $5 \mathrm{c}$ and $5 \mathrm{~d}$ ), despite their being available for free from numerous research and distribution sources.

Images, and their design and presentation, have effects on the attention of both spectators (Smeesters; Mandel, 2006; Andreu-Sánchez et al., 2017; 2018) and consumers (Nebenzahl; Jaffe; Lampert, 1997). The power of words and images in advertising has been demonstrated and studied for years (Snyder; DeBono, 1985; Andreu-Sánchez; Martín-Pascual, 2014). Likewise, the visual supports that accompany informative scientific texts have a clear effect on how the general public judges scientific reasoning and the credibility of scientific information (McCabe; Castel, 2008; Keehner; Mayberry; Fischer, 2011).

The purpose of this investigation is to determine the nature of SARS-CoV-2 coronavirus images that were available on the internet at the beginning of the declaration of the Covid-19 pandemic, on March 11, 2020.

\section{Methods}

This article studies the images related to the SARS-CoV-2 coronavirus available on the internet during the start of the first Covid-19 pandemic. To do this, we carried out a systematic search for images using various search engines (Google search images, Duck duck go images, and Yahoo images) from different devices and IP addresses, all located in Spain, between March 10 and 16, 2020. We searched using the terms "SARS-CoV-2" and "Covid-19". We selected the images that referred to the coronavirus, avoiding images of hospitals, patients, or others. A total of 71 different images of the coronavirus were collected by these searches. During that same time period, we traced their sources and recorded them in a document.

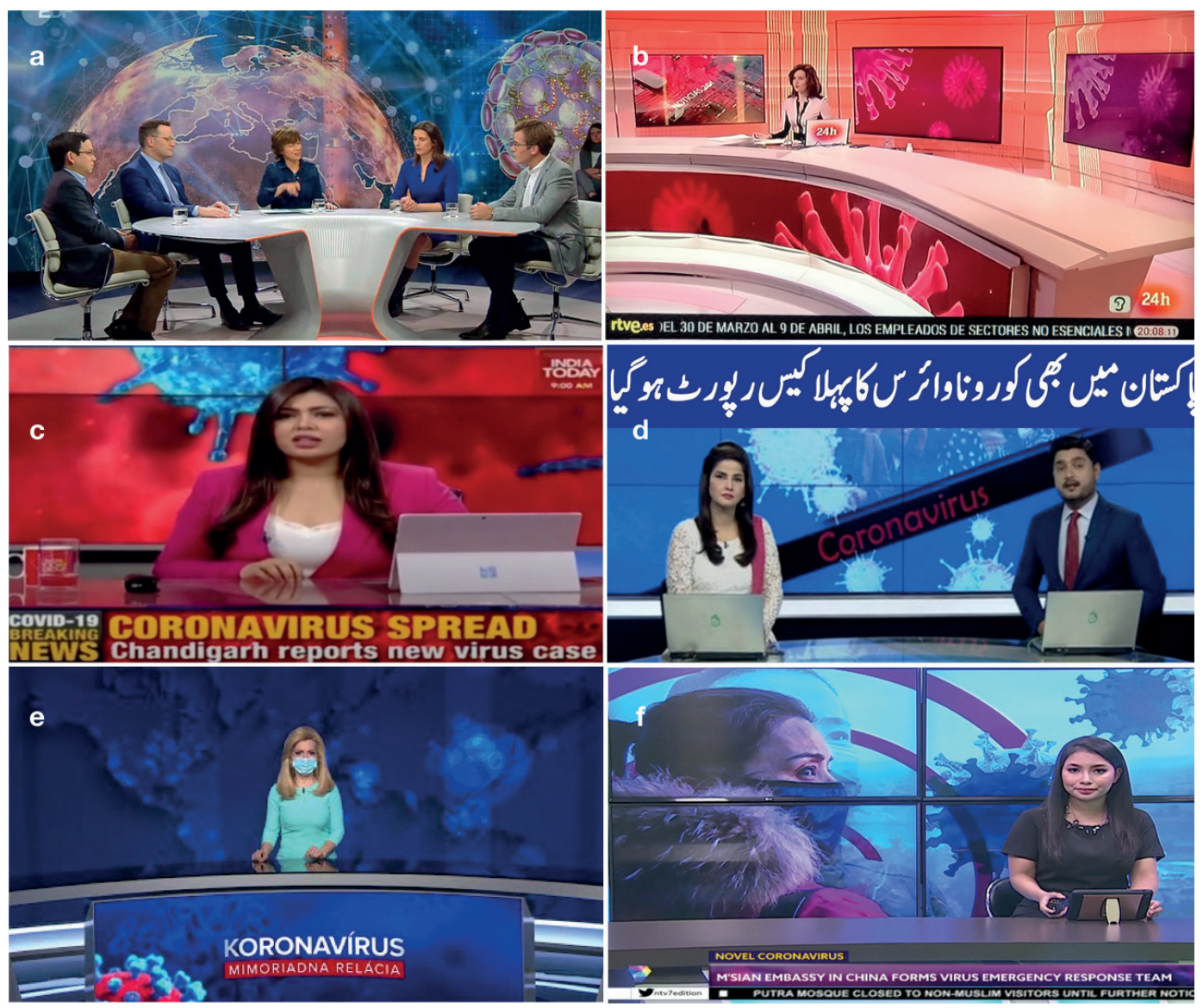

Figure 4. Some examples of the adaptation of coronavirus images to the chromatic esthetics of the media.

a. Debate program, note that on the right they have wrapped the Earth with the coronavirus cover, ZDF, Germany.

b. Canal 24horas in RTVE, Spain.

c. News on India Today, India.

d. K21 News, Pakistan.

e. News on TV Markiza, Slovakia.

f. NTV7, Malaysia. 

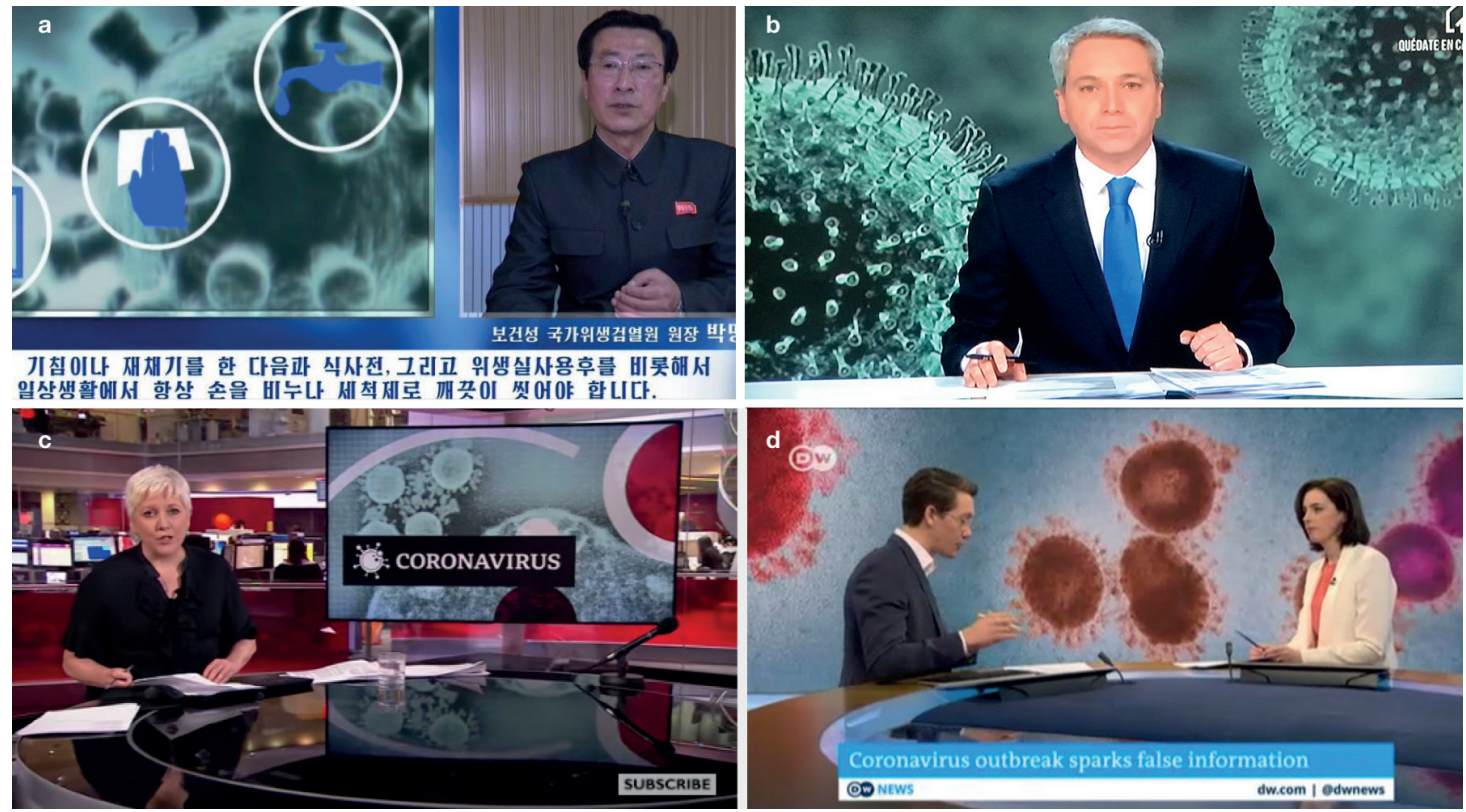

Figure 5. Coronavirus models that do not correspond to SARS-CoV-2 and are not real $(\mathrm{a}, \mathrm{b})$ and real models, scarce in the media, that are retouched (c, d). a. Central Korea TV show, North Korea.

b. Antena 3 news, Spain.

c. A slightly realistic image, $B B C$ News, UK.

d. One of the few TV channels that regularly uses real images, even if they are retouched, Deutsche Welle, Germany.

We studied all the images considering two parameters: their attributes and their sources. In identifying the attributes, we considered whether the images were photographs or illustrations, whether they were black and white or color, and whether they were two- or three-dimensional. For the study of the sources, we traced where these images were published during the selected period of time and noted the first two web pages that presented the images. We performed a reverse search to triangulate the results.

We used a spreadsheet for the database, Sigmaplot 11.0 (Systat Software Inc.) to perform statistical calculations, and Circus (Krzywinski et al., 2009) for the visual representation of the results.

\section{Results}

Of the total images $(n=71$ ), $70.4 \%$ were illustrations while only $29.6 \%$ were photographs. Note that not all the photographs corresponded to SARS-CoV-2, being microscopic photographs of unspecified viruses. Viruses from animals, various representations of influenza viruses, and representations of viruses invented through the imagination of design artists were identified in the illustrations. Most of the images (90.1\%) were in color, a curious fact as color microscopic photographs are not typical in the scientific field. Electron microscopes, whether scanning tunneling or cryogenic, operate in grayscale, while color is added later using image retouching programs. Many of the photographic images included color (71.4\%), which shows an interest in converting scientific figures for esthetic reasons, although the use of color for pedagogical reasons to distinguish coronaviruses from the surrounding biological tissue was also sometimes justified (see NIAID images in Figure 1). Of the images, $70.4 \%$ were in three dimensions, and once again it is interesting to note that only $29.6 \%$ of the images were in two dimensions, which is the usual way of representing microscope images in a real and scientific way (see Table 1).
Table 1. Categorization of the studied images and the number and percentage of those obtained in the sample $(n=71)$

\begin{tabular}{|l|l|c|c|}
\hline \multirow{3}{*}{ Image type } & Photography & 21 & $29,6 \%$ \\
\cline { 2 - 4 } & Illustration & 50 & $70,4 \%$ \\
\hline \multirow{3}{*}{ Color } & Black and white & 7 & $9,9 \%$ \\
\cline { 2 - 4 } & Color & 64 & $90,1 \%$ \\
\hline \multirow{3}{*}{ Image depth } & 2D & 21 & $29,6 \%$ \\
\cline { 2 - 4 } & $3 \mathrm{D}$ & 50 & $70,4 \%$ \\
\hline
\end{tabular}


These results point to a significantly greater use of color, $3 \mathrm{D}$, and illustration in the visual representation of the coronavirus. Thus, we see that the images used, at least initially, to present SARS-CoV-2 information were mostly not real.
The use of incorrect images of the SARS-

CoV-2 coronavirus seems to be a manifestation of a low-intensity infodemic

On the other hand, we found several positive correlations between the attributes of the images:

- photography - black and white $(r=0.928, p=0.023)$,

- photography-2D $(r=0.995, p=0.0004)$,

- illustration-color $(r=0.994, p=0.0005)$,

- illustration-3D ( $r=0.999, p=0.00003)$,

- black and white-2D ( $r=0.93, p=0.02)$,

- color-3D ( $r=0.993, p=0.0008)$.

Graph 1 presents a chord diagram showing the individual distribution of the attributes in each studied image.

We also studied the sources of information in which these images were found. We found that, of the 71 images (see Table 2):

- 32 were on medical and/or scientific information websites;

- 31 in the media;

- 15 in image repositories;

- 12 on institutional websites; and

- 4 in encyclopedias (Wikipedia and Encyclopaedia Britannica).

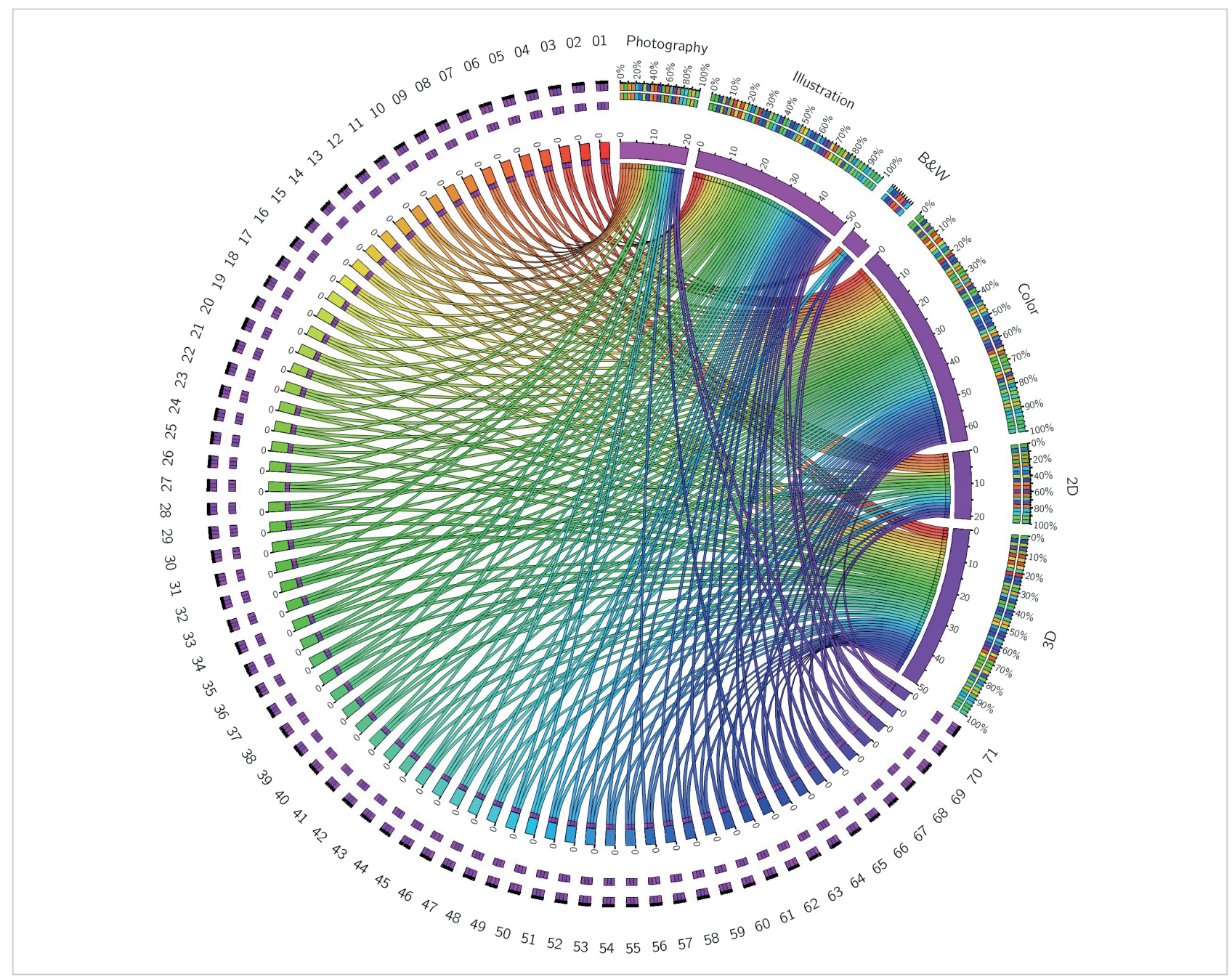

Graph 1. Chord diagram with the formal categories of the images and the sample of collected images. Each number corresponds to one of the sample images. Each string indicates the connection between the image and the image attribute studied. Note the smaller number of photos, 2D, and blackand-white images, which usually correspond to real images of SARS-CoV-2. 
Table 2. Information sources that contained the analyzed images. There is a total of 75 sources, distributed in five categories. Some images were in various sources at the same time, sometimes with minor variations in number, shape, or color. And some sources had several of the studied images. Source: authors' elaboration.

\begin{tabular}{|c|c|c|}
\hline Source type & Number & Sources \\
\hline $\begin{array}{l}\text { Medical and/or scientific } \\
\text { information websites }\end{array}$ & 32 & $\begin{array}{l}\text { NIAID (x2), Medical News Today (x2), The Lancet (x2), Thailand Medical News (x2), Hospital Vall d'He- } \\
\text { bron, Agencia Sinc, Idescubre, Intermountain Healthcare, Dr. Diyorki, AARP, Labmedica, Creative Biolabs, } \\
\text { Su doctor informa, Covid-19portal, Naked Science, diabetes connections, Nexu Science Communication, } \\
\text { Positively Aware, Consorci sanitari de I'Alt Penedès, Biorxiv, GEN. Genetic Engineering \& Biotechnology } \\
\text { News, Innophore, virology blog, Medscape, The Scientist, The Native Antigen Company, Xenex, Drug Tar- } \\
\text { get Review }\end{array}$ \\
\hline Media & 31 & $\begin{array}{l}\text { Express (x3), CNN (x2), BBC (x2), MSN (x2), Eurasiareview, The Sydney Morning Herald, as, Rtve, Oman } \\
\text { Observer, Arabian Business, Daily Mail, Radio San Joaquín, FSR magazine, Techylawyer, Daily Star, Mi- } \\
\text { rror, Bussiness Today, Con nuestro Perú, } 20 \text { minutos, ¡Hola! México, Sputnik mundo, CatalunyaPress, El } \\
\text { mundo, The Wall Street Journal, Aljazeera, Correo del Orinoco }\end{array}$ \\
\hline Image repositories & 15 & $\begin{array}{l}\text { iStock (x3), Pixabay (x3), Getty Images (x3), Dreamstime, Fine Art America, Science Photo, Tosshub, Shu- } \\
\text { tterstock, Turbosquid }\end{array}$ \\
\hline Institutional websites & 12 & $\begin{array}{l}\text { Københavns Professions Højskole (University College Copenhagen) (x3), Universitat Internacional de Ca- } \\
\text { talunya, United Nations, University of Georgia, Scotch College, University of Michigan, Universidad del } \\
\text { Desarrollo, University of Washington, Czech Republic Tourism, Universitat de Barcelona }\end{array}$ \\
\hline Encyclopedias & 4 & Wikipedia (x3), Encyclopaedia Britannica \\
\hline
\end{tabular}

The analyzed images were found in 75 sources, mainly in the general media and on websites containing medical and/or scientific information. There were:

- 28 sources of medical and/or scientific information, including websites of medical centers, communication agencies, and scientific media, scientific information blogs and pages of medical companies, and/or scientific services that offer information on SARS-CoV-2.

- 26 media sources not specialized in medical or scientific information.

- 10 institutional websites as sources of information, 8 of them being pages of university centers, one from the United Nations, and the other corresponding to the tourism office of a country.

- 9 repositories, containing both any type of image and scientific images. Most of the images in these repositories are paid. One can also find images from free scientific sources for sale in these repositories.

- Finally, the encyclopedic sources found correspond to Wikipedia and Encyclopaedia Britannica.

We then considered the distribution in different categories, to determine the relationship between the types of sources and the attributes of the images, but did not find a significant relationship $\left(\chi^{2}=26.082, p=0.163\right)$. The images used may be photographs (real or true images) or illustrations (not real or false images). Illustrations predominate over photographs in most types of sources:

- repositories (86.6\%)

- media (58.1\%)

- medical and/or scientific information websites (71.9\%)

- institutional websites (83.3\%) and

- encyclopedias (25\%).

Only in encyclopedias (Wikipedia and Encyclopaedia Britannica) the use of real photographs exceed the use of illustrations to inform about the SARS-CoV-2 coronavirus.

\section{Discussion and conclusions}

These results represent a sample of the images used for educational and reporting purposes in the early days of the SARS-CoV-2 pandemic on the internet. This is a period of time during which internet searches for the terms "SARSCoV-2" and especially "Covid-19" increased progressively (De-la-Serna, 2020). Through this research, we see what kinds of images were presented to citizens on the internet in that initial time.

Based on these results, the reference image used in the media and other sources on the coronavirus causing Covid-19 is a retouched design image for illustration, in color and three dimensions, rather than a real image.

These results are interesting given that the first image of the SARS-CoV-2 coronavirus dates from January 24, 2020 and, with more quality, from February 13 of the same year. The predominance of 3D color illustrations was not a forced selection due to the lack of real publications as of March 2020, but content creators opted for more artistic or esthetic options. The original scientific images did not take on the importance that they should perhaps have had in such an informational emergency situation. These results cause us to reflect and ask ourselves whether we would be willing to be informed about other types of

Many of the virus images used to report SARS-CoV-2 or Covid-19 are representations of viruses that affect animals, other different respiratory coronaviruses, or other diseases such as influenza 
real content using imaginary illustrations. It seems that we are in the era prior to photography, when illustrators represented the reality of information (Peláez-Malagón, 1998). The scientific dissemination on Covid-19 uses more visual metaphors or drawings in preference to the scientific reality as captured by microscopic photography. Biomedical information transmitted by the media is of great value for citizens to make decisions regarding their health (Casino, 2019), so it would be good for journalists and communicators in general to become aware and carry out a reflection exercise in this regard.

Image banks are a source of essential resources for any content creator, but their increasing use causes the world's media to resemble each other more and present a very similar visual world (Machin, 2004). Although it is true that they are very useful, there are areas such as the scientific field in which material should be sought from contrasted sources and not banks of artistic images. Many public scientific organizations (National Institute of Allergy and Infectious Diseases, NIAID, National Institutes of Health, NIH, National Aeronautics and Space Administration, NASA, among others) offer free use of their content. In addition, during the Covid-19 pandemic, many commercial scientific publishers (Taylor and Francis Group, Cambridge University Press, Springer Nature, and Elsevier, among others) left open all their content related to the SARS-CoV-2 coronavirus. Therefore, access to real information and photos is not a problem preventing information providers and communicators from using real scientific sources. In addition, since content copyright has a direct influence on communication practice (Oppenheim, 2020), this specific trend of open research publication eliminates the differences between media with different economic levels.

The illustrations shown in the information in the context of the Covid-19 crisis are fundamental, since we know that the form of visual presentations has an impact on the attention of the viewer (Andreu-Sánchez et al., 2017; 2018). Although it is true that what has the greatest impact in this crisis is the deaths, it is known that the attributes and colors of images impact on emotions (Barry, 2009). Therefore, future research is necessary to determine the emotional impact that this may have had on society.

Often, these fake images are used to decorate a set that is used to provide information (see Figures 3, 4, and 5). Other times, the recreated virus images are used in news on the web and to illustrate information about the coronavirus or its disease. It even seems that the attribution of the images, many to a photo repository instead of a laboratory or research center, provides them with legitimacy. This lack of rigor in coronavirus images is not only due to their metaphorical use. The use of unrealistic (or fake) images of the SARS-CoV-2 coronavirus seems to be a manifestation of a low-intensity infodemic. This does not represent a disinformation hoax, but it affects the rigor of the news to various degrees. Here, too, content reception research is needed to confirm how the content presented is interpreted, especially if such retouched or erroneous images are used to illustrate information. Many of the images used to report on SARS-CoV-2 or Covid-19 are depictions of viruses from cats or other animals, other diseases such as influenza, or other respiratory coronaviruses other than that identified as causing Covid-19. A possible solution would be to be especially careful in attributing and explaining the genesis of the images used. On the one hand, this has ethical implications regarding the rigor of information and knowledge management, but on the other, it seems to have economic interests regarding the generation of esthetic assets for paid image repositories. The large number of reconstructions of SARS-CoV-2 have created a chimera of disinformation that is increasingly distant from the appearance of the real coronavirus that causes Covid-19.

Most of the SARS-CoV-2 coronavirus images in the sample used in this work are unrealistic reconstructions or alterations (70.4\%). Often, the most realistic photographic representations are also altered by the use of false color ( $71.4 \%$ of all the studied photographs), although logically, this affects the illustrative rigor of the news about Covid-19 less than the use of erroneous images.

As information professionals, we must use, when possible, rigorous real images of SARS-CoV-2, just as we would do with any other target of information provision.

\section{References}

Adhanom-Ghebreyesus, Tedros (2020). Munich security conference. Munich: World health organization. https://www.who.int/dg/speeches/detail/munich-security-conference

Andreu-Sánchez, Celia; Martín-Pascual, Miguel-Ángel (2014). "Representation of neuroscience in advertising". In: Grabowski, Michael. Neuroscience and media: New understandings and representations. USA: Routledge, pp. 183-193. ISBN: 9781138811508

http://www.routledge.com/books/details/9781138811508 
Andreu-Sánchez, Celia; Martín-Pascual, Miguel-Ángel; Gruart, Agnès; Delgado-García, José-María (2017). “Eyeblink rate watching classical hollywood and post-classical MTV editing styles, in media and non-media professionals". Scientific reports, v. 7, art. 43267.

https://doi.org/10.1038/srep43267

Andreu-Sánchez, Celia; Martín-Pascual, Miguel-Ángel; Gruart, Agnès; Delgado-García, José-María (2018). “Chaotic and fast audiovisuals increase attentional scope but decrease conscious processing". Neuroscience, v. 394, pp. 83-97. https://doi.org/10.1016/j.neuroscience.2018.10.025

Barry, Ann-Marie (2009). "Perceptual aesthetics: Transcendent emotion, neurological image". Visual communication quarterly, v. 13, n. 3, pp. 134-151. https://doi.org/https://doi.org/10.1207/s15551407vcq1303_2

Casero-Ripollés, Andreu (2020). "Impact of Covid-19 on the media system. Communicative and democratic consequences of news consumption during the outbreak". El profesional de la información, v. 29, n. 2, e290223.

https://doi.org/10.3145/epi.2020.mar.23

Casino, Gonzalo (2019). "Retos y perspectivas en el ecosistema de la información biomédica". El profesional de la información, v. 28, n. 2, e280205.

https://doi.org/10.3145/epi.2019.mar.05

De-la-Serna, Juan-Moisés (2020). Aspectos psicológicos del Covid-19. La Rioja: Editorial Tektime. ISBN: 9788835404484 https://www.researchgate.net/publication/340536973_Aspectos_Psicologicos_del_COVID-19

De-Wit, Emmie; Fisher, Elizabeth; Offic, Rocky Mountain Laboratories Visual Medical Arts (2020). "Novel coronavirus 2019". NIAID Flickr.

https://www.flickr.com/photos/niaid/albums/72157712914621487

Depoux, Anneliese; Martin, Sam; Karafillakis, Emilie; Preet, Raman; Wilder-Smith, Annelies; Larson, Heidi (2020). "The pandemic of social media panic travels faster than the Covid-19 outbreak". Journal of travel medicine, taaa031. https://doi.org/10.1093/jtm/taaa031

Eckert, Alissa; Higgins, Dan (2020). "Public health image libray (PHIL)". Centers for Disease Control and Prevention (CDC). https://phil.cdc.gov/details.aspx?pid=23312

Egerton, Ray F. (2016). Physical principles of electron microscopy. USA: Springer, ISBN: 9780387258000 https://doi.org/10.1007/978-3-319-39877-8

European Broadcasting Union (2020a). Covid-19 PSM audience performance. Europe: EBU Media Intelligence Service. https://www.ebu.ch/publications/research/membersonly/report/covid-19-crisis-psm-audience-performance

European Broadcasting Union (2020b). Covid-19 crisis. Impact on digital media consumption. Europe: EBU Media Intelligence Service. https://www.ebu.ch/publications/research/membersonly/report/covid-19-crisis-the-impact-on-digital-media-consumption

Garrett, Laurie (2020). "The art of medicine Covid-19: the medium is the message". The lancet, 11 March. https://doi.org/10.1016/S0140-6736(20)30600-0

Gorbalenya, Alexander E.; Baker, Susan C.; Baric, Ralph S.; De-Groot, Raoul J.; Drosten, Christian; Gulyaeva, Anastasia A.; Haagmans, Bart L.; Lauber, Chris; Leontovich, Andrey M.; Neuman, Benjamin W.; Penzar, Dmitry; Perlman, Stanley; Poon, Leo L. M.; Samborskiy, Dmitry; Sidorov, Igor A.; Sola, Isabel; Ziebuhr, John (2020). "Severe acute respiratory syndrome-related coronavirus: The species and its viruses, a statement of the coronavirus study group". bioRxiv, 11 February. https://doi.org/10.1101/2020.02.07.937862

Hua, Jinling; Shaw, Rajib (2020). “Corona virus (Covid-19) 'infodemic' and emerging issues through a data lens: The case of China". International journal of environmental research and public health, v. 17, n. 7, 2309. https://doi.org/10.3390/ijerph17072309

Keehner, Madeleine; Mayberry, Lisa; Fischer, Martin H. (2011). “Different clues from different views: The role of image format in public perceptions of neuroimaging results". Psychonomic bulletin and review, v. 18, n. 2, pp. $422-428$. https://doi.org/10.3758/s13423-010-0048-7

Krzywinski, Martin; Schein, Jacqueline E.; Birol, Inanc; Connors, Joseph; Gascoyne, Randy; Horsman, Doug; Jones, Steven J.; Marra, Marco A. (2009). "Circos: an information aesthetic for comparative genomics". Genome research, v. 19, n. 604, pp. 1639-1645.

https://doi.org/10.1101/gr.092759.109

Legido-Quigley, Helena; Mateos-García, José-Tomás; Regulez-Campos, Vanesa; Gea-Sánchez, Montserrat; Muntaner, Carles; McKee, Martin (2020). "The resilience of the Spanish health system against the Covid-19 pandemic". The lancet public health, v. 2667, n. 20, pp. 19-20.

https://doi.org/10.1016/S2468-2667(20)30060-8 
Li, Cuilian; Chen, Li Jia; Chen, Xueyu; Zhang, Mingzhi; Pang, Chi-Pui; Chen, Haoyu (2020). "Retrospective analysis of the possibility of predicting the Covid-19 outbreak from internet searches and social media data, China, 2020". Euro surveiIlance: Bulletin Europeen sur les maladies transmissibles = European communicable disease bulletin, v. 25, n. 10, pp. 1-5. https://doi.org/10.2807/1560-7917.ES.2020.25.10.2000199

Liu, Chuang; Yang, Yang; Gao, Yuanzhu; Shen, Chenguang; Ju, Bin; Liu, Congcong; Tang, Xian; Wei, Jinli; Ma, Xiaomin; Liu, Weilong; Xu, Shuman; Liu, Yingxia; Yuan, Jing; Wu, Jing; Liu, Zheng; Zhang, Zheng; Wang, Peiyi; Liu, Lei (2020). "Viral architecture of SARS-CoV-2 with post-fusion spike revealed by Cryo-EM". bioRxiv, 5 March. https://www.biorxiv.org/content/10.1101/2020.03.02.972927v1.abstract

Machin, David (2004). "Building the world's visual language: The increasing global importance of image banks in corporate media". Visual communication, v. 3, n. 3, pp. 316-336.

https://doi.org/10.1177/1470357204045785

McCabe, David P.; Castel, Alan D. (2008). "Seeing is believing: the effect of brain images on judgments of scientific reasoning". Cognition, v. 107, n. 1, pp. 343-352.

https://doi.org/10.1016/j.cognition.2007.07.017

National Microbiology Data Center (2020). “新型冠状病毒武汉株01 / C-Tan-nCov Wuhan strain 01”. Novel Coronavirus National Science and Technology Resource Service System.

http://nmdc.cn/nCov/en

Nebenzahl, Israel D.; Jaffe, Eugene D.; Lampert, Shlomo I. (1997). "Towards a theory of country image effect on product evaluation". Management international review, v. 37, n. 1, pp. 27-49.

Nielsen, Rasmus-Kleis; Fletcher, Richard; Newman, Nic; Brennen, J. Scott; Howard, Philip N. (2020). Navigating the 'infodemic': How people in six countries access and rate news and information about coronavirus. UK: The Reuters Institute for the Study of Journalism y University of Oxford. ISBN: 9781907384745

https://bit.ly/2WvmMTR

Office of Communications (Ofcom) (2020). Covid-19 news and information: consumption and attitudes. Results from week one of Ofcom's online survey. UK: Ofcom.

https://cutt.ly/EyWRORG

Oppenheim, Charles (2020). "A copyright overview". El profesional de la información, v. 29, n. 1, e290106. https://doi.org/10.3145/epi.2020.ene.06

Peláez-Malagón, José-Enrique (1998). La ilustración gráfica y la caricatura en la prensa valenciana del siglo XIX. Tesis doctoral. Valencia: Universitat de València.

http://roderic.uv.es/handle/10550/38547

Shimizu, Kazuki (2020). “2019-nCoV, fake news, and racism”. The lancet, v. 395, n. 10225, pp. 685-686. https://doi.org/10.1016/S0140-6736(20)30357-3

Smeesters, Dirk; Mandel, Naomi (2006). "Positive and negative media image effects on the self". Journal of consumer research, v. 32, n. 4, pp. 576-582.

https://doi.org/10.1086/500489

Snyder, Mark; DeBono, Kenneth G. (1985). "Appeals to image and claims about quality: understanding the psychology of advertising". Journal of personality and social psychology, v. 49, n. 3, pp. 586-597.

https://doi.org/10.1037/0022-3514.49.3.586

The lancet (2020). “Covid-19: fighting panic with information”. The lancet, v. 395, n. 10224, p. 537.

https://doi.org/10.1016/S0140-6736(20)30379-2

Toffler, Alvin (1980). The third wave. New York: William Morrow. ISBN: 9780688035976

Torres-Salinas, Daniel (2020). “Ritmo de crecimiento diario de la producción científica sobre Covid-19. Análisis en bases de datos y repositorios en acceso abierto". El profesional de la informacion, v. 29, n. 2, e290215.

https://doi.org/10.3145/epi.2020.mar.15

Wu, Aiping; Peng, Yousong; Huang, Baoying; Ding, Xiao; Wang, Xianyue; Niu, Peihua; Meng, Jing; Zhu, Zhaozhong; Zhang, Zheng; Wang, Jiangyuan; Sheng, Jie; Quan, Lijun; Xia, Zanxian; Tan, Wenjie; Cheng, Genhong; Jiang, Taijiao (2020a). "Genome composition and divergence of the novel coronavirus (2019-nCoV) originating in China". Cell host and microbe, v. 27, n. 3, pp. 325-328.

https://doi.org/10.1016/j.chom.2020.02.001

Wu, Fan; Zhao, Su; Yu, Bin; Chen, Yan-Mei; Wang, Wen; Song, Zhi-Gang; Hu, Yi; Tao, Zhao-Wu; Tian, Jun-Hua; Pei, Yuan-Yuan; Yuan, Ming-Li; Zhang, Yu-Ling; Dai, Fa-Hui; Liu, Yi; Wang, Qi-Min; Zheng, Jiao-Jiao; Xu, Lin; Holmes, Edward C.; Zhang, YongZhen (2020b). "A new coronavirus associated with human respiratory disease in China”. Nature, v. 579, n. 7798, pp. 265-269. https://doi.org/10.1038/s41586-020-2008-3 